\title{
A NUMERICAL SIMULATION OF MORPHOLOGICAL PROCESSES FOR A NAVIGATION CHANNEL
}

\author{
NGUYEN VAN DIEP and DANG HUU CHUNG \\ Institute of Mechanics, NCNST of Vietnam
}

\begin{abstract}
SUMMARY. The finite difference method was apptied to simulate the morphological processes for a navigation channel. Mathematical equations were based on the SUTRENCH and PROFILE models proposed by L. C. van Rijn. The difficulties of treatment for bed boundary conditions were overcame flexibly by using the interpolation functions with high accuracy. The results obtained showed that the simulation is very suitable and able to be applied to practice problems.
\end{abstract}

\section{INTRODUCTION}

The morphological process is a popular phenomenon happening in rivers, estuaries and coastal regions, especially in environments with a predominant suspended load. According to Ida Broker Hedegaard et al. [2] that is the interaction between hydrodynamic conditions and bed level evolution. This problem has been interesting several scientists in the world. Up to now there are many mathematical models for this [7], but the model in which the turbulence of flow is taken into account, may be more suitable. Knowledge on this process is really necessary because several studies in practice are required, such as harbour project, in which the rate of sedimentation in the navigation channel may be one of the most important economic aspects, and can be the parameter that finally decides the optimal location of the harbour.

\section{MATHEMATICAL MODEL}

Using the assumptions of the quasi-steady flow, the longitudinal diffusion term being neglected in comparision with the vertical diffusion term and the one of unsteady concentration being relatively small in relation to the others, the system of equations describing sediment flow perpendicular to channel axis are as follows $|5-6|$

$$
\begin{aligned}
& u=A_{1} u_{h_{2}} \ln \left(\bar{z} / z_{0}\right)+u_{h_{2}}\left(1-A_{1} h \ln \left(h / z_{0}\right)\right)\left(2 \eta^{r}-\eta^{2 r}\right) \\
& \frac{1}{b} \frac{\partial}{\partial x}(b u)+\frac{\partial w}{\partial z}=0 \\
& \frac{1}{b} \frac{\partial}{\partial x}(b u c)+\frac{\partial}{\partial z}\left(w-w_{*}\right) c-\frac{\partial}{\partial z}\left(\varepsilon_{s} \frac{\partial c}{\partial z}\right)=0 \\
& b \frac{\partial z_{k}}{\partial t}+\frac{1}{(1-p)} \frac{\partial}{\partial x}\left(s_{s}+s_{h}\right)=0
\end{aligned}
$$

in which $u, w$ are the time-averaged fluid velocities in $x, z$ direction, respectively, $z_{k}$, the bed level with respect to horizontal datum, $\bar{z}$ height above bed $\left(z=\bar{z}+z_{h}\right), u_{h}$ flow velocity at water surface $(\bar{z}=h), z_{0}$ zero-velocity level $\left(z_{1}=0.03 k_{*}\right), k_{s}$ effective roughness heiglit, $h \cdot$ water depth, $b$ the width of the flow, $\eta=\left(\bar{z}-z_{11}\right) /\left(h-z_{11}\right), A_{1}, r$ dimensionless variables to determine, $c$ the 
time-averaged sediment volune concentration, $w_{*}$ the particle fall velocity, $\varepsilon$, the sediment usixing coefficient, $t$ the time, $p$ the porosity of bed material, and $s_{*}$, $s_{1}$, the cross section-integrated suspended load and bed load transports, respectively. The suspended load transport is defined as

$$
s_{s}=b \int_{z_{b}+2}^{z_{t}+h} u c d z
$$

in which $a$ is the reference level; and the bed load transport is determined by a stochastic function proposed by van Rijn [5-6]:

$$
s_{1}=0.1 b(\Delta g)^{1.5} d_{50}^{1.5} \frac{\overline{T_{m b}^{2.1}}}{D_{*}^{1.3}}
$$

with

$$
\begin{aligned}
& \overline{T_{m, 2}^{2.1}}=\frac{1}{(2 \pi)^{0.5}}\left[\left(\frac{\sigma^{\prime}}{\tau_{b, c r .1}}\right)^{2.1} I_{3}+\left(\frac{\sigma^{\prime}}{\tau_{b, c r, 2}}\right)^{2.1} I_{4}\right], \\
& I_{3}=\int_{0}^{\infty} x^{2.1} e^{-(x-r)^{2} / 2} d x, I_{4}=-\int_{0}^{\infty} x^{2.1} e^{-(x-\eta)^{3} / 2} d x, \\
& \therefore \Delta=\frac{\rho_{s}-\rho}{\rho}, \quad D_{*}=d_{50}\left(\Delta g / \nu^{2}\right)^{1 / 3}, \quad r=\frac{\overline{\tau_{b}^{\prime}}-\tau_{b, c r, 1}}{\sigma^{\prime}}, \\
& p=\frac{\tau_{b}^{\prime}-\tau_{b, c r .2}}{\sigma^{\prime}}, \overline{\tau_{b}^{\prime}}=\rho g\left(\bar{u} / C^{\prime}\right)^{2}, \quad C^{\prime}=18 \log \left(4 h / d_{90}\right) \\
& \tau_{b, c r, 1}=\tau_{b, c r}^{0} \frac{\sin (\phi+\alpha)}{\sin \phi}, \tau_{b, c r .2}=\tau_{h, c r}^{\prime \prime} \frac{\sin (\phi-\alpha)}{\sin \phi}, \text { when } \frac{\partial h}{\partial x} \leq 0 \\
& \tau_{b, c r .1}=\tau_{b, c r}^{0} \frac{\sin (\phi-\alpha)}{\sin \phi}, \tau_{h, c r .2}=\tau_{b, c r}^{\prime \prime} \frac{\sin (\phi+\alpha)}{\sin \phi}, \text { when } \frac{\partial h}{\partial x}>0 \\
& \tau_{b, c r}^{0}=1.5 \bar{r}_{b, c r}^{0}
\end{aligned}
$$

where $D_{*}$ is the dimensionless diameter of particle, $d_{50}$ and $d_{90}$ the particle diameters of bed material, $C^{\prime}$ the Chezy coefficient related to grains, $\Delta$ the relative density, $\nu$ the kinematic viscosity coefficient, $\sigma^{\prime}$ the standard deviation of bed-shear stress (after van Rijn $\sigma^{\prime}=0.4 \overline{\tau_{b, 1}^{\prime}}$ with $\overline{\tau_{b, 0}^{\prime}}$ is effective bed-shear stress at $x=0$ ), $\overline{\tau_{h}^{\prime}}$ the time-averaged bed-shear stress, $\tau_{b, c r, 1}$ and $\tau_{b, c, 2}$ the instantaneous critical bed-shear stress in and against flow direction, respectively, $\bar{r}_{b, r, r}^{\prime \prime}$ the mean critical bed shear stress at a horizontal bed according to Shields, $\phi$ the angle of internal friction, $\alpha$ the bed slope angle, and $\bar{u}$ is the depth-averaged fluid velocity in $x$ direction.

The formula (2.1) was obtained by L.C. van Rijn on the base of Coles' result (1965) for determination of the velocity profile in nonuniform flow. As it depends on three unknown variables $A_{1}, r, u_{h}$, so three more equations are needed to close the system of equations. They are

$$
\begin{aligned}
Q & =b \int_{z_{0}}^{h} u d \bar{z} \\
\frac{-1+\ln \left(h / z_{0}\right)}{\ln \left(0.5 h / z_{0}\right)} & =\frac{3 r+1}{\left(2 r^{2}+3 r+1\right)\left[2(0.5)^{r}-(0.5)^{2 r}\right]} \\
& \simeq 0.16 r^{2}-0.29 r+1.02 \\
\frac{d u_{h_{h}}}{d x} & =\alpha_{1} \frac{u_{h t}}{h}-\alpha_{2} \frac{u_{h}}{h}-\alpha_{3} \frac{u_{h}}{b}
\end{aligned}
$$


with

$$
\begin{aligned}
& u_{h e}=\frac{g^{n .5} \ln \left(h / z_{0}\right)}{\kappa C} \overline{\bar{u}}, \overline{\bar{u}}=\frac{Q}{b h}, C=18 \log \left(12 h / k_{*}\right) \\
& \alpha_{1}=0.28+0.11 \tanh (6(d h / d x)-0.15) \\
& \alpha_{2}=0.235+0.065 \tanh (17(d h / d x-0.035)) \\
& \alpha_{3}=0.1 \tanh (10 d b / d x)
\end{aligned}
$$

in which eq.(2.7) is the continuity equation, eq.(2.8) $r$ parameter equation established by using the equilibrium mid-depth velocity of logarithmic distribution in eq.(2.1), eq.(2.9) the water surface velocity equation, $u_{h}$ the surface velocity for equilibrium flow, $\overline{\bar{u}}$ the crossection-averaged flow velocity, $C$ the Chezy coefficient, $\alpha_{1}, \alpha_{2}$ and $\alpha_{3}$ the empirical coefficients, $g$ the acceleration of gravity, and $\kappa$ the constant of Von Karman.

In the case of consideration the sediment mixing coefficient, $\varepsilon_{y}$, is approximately equal to the fluid mixing coefficient, $\varepsilon_{f}$, that is used usually from parabolic-constant distribution

$$
\varepsilon_{f}= \begin{cases}\varepsilon_{f, \text { max }}-\varepsilon_{f, \max }(1-2 \bar{z} / h)^{2}, & \text { for } \frac{\bar{z}}{h}<0.5 \\ \varepsilon_{f, \max x}, & \text { for } \frac{\bar{z}}{h} \geq 0.5\end{cases}
$$

with

$$
\begin{aligned}
& \frac{d \varepsilon_{f, \max x}}{d x}=\left(\frac{\alpha_{4}}{h}\left(\varepsilon_{f, \max , e}-\varepsilon_{f, \operatorname{mul} x_{x}}\right)-\alpha_{5} h \frac{d\left(u_{h}-\overline{\bar{u}}\right)}{d x}\right) \cdot \exp \left(-15 \frac{d h}{d x}\right) \\
& \varepsilon_{f, \max , e}=0.25 \kappa u_{*, e} h, u_{*, e}=\frac{\kappa \overline{\bar{u}}}{-1+\ln \left(h / z_{0}\right)}, \alpha_{4}=0.05, \alpha_{5}=0.015
\end{aligned}
$$

where $\varepsilon_{f, m u x . e}$ is the maximum fluid mixing coefficient for equilibrium conditions, $u_{*, e}$ the equilibrium bed-shear velocity, and $\alpha_{4}$ and $\alpha_{5}$ the empirical coefficients

\section{INITIAL AND BOUNDARY CONDITIONS}

In general the following conditions are required

$$
\begin{aligned}
& \left.z_{l,}(x, t)\right|_{t=0}=f_{1}(x), Q=f_{2}(t), \\
& \left.u(x, z, t)\right|_{x=0}=f_{3}(z, t),\left.c(x, z, t)\right|_{x=0}=f_{4}(z, t), \\
& w_{\star} c+\varepsilon_{*} \frac{\partial c}{\partial z}=0 \quad \text { at } z=z_{l}+h \\
& -\varepsilon_{*} \frac{\partial c}{\partial z}=E_{t, \varepsilon} \quad \text { at } z=z_{b}+a
\end{aligned}
$$

in which $f_{i}(i=1,2,3,4)$ are known functions, $E_{\text {the. }}$ is the equilibrium upwards diffusive sediment flux established by van Rijn as follows [6] :

$$
E_{\text {c }, e}=0.03 w_{*} \frac{d_{50}}{a} \frac{\overline{T_{r t i}^{1.5}}}{D_{*}^{0.3}}
$$

where

$$
\begin{aligned}
& \overline{T_{m}^{1.5}}=\frac{1}{(2 \pi)^{0.5}}\left[\left(\frac{\sigma^{\prime}}{\tau_{b, c r .1}}\right)^{1.5} I_{1}+\left(\frac{\sigma^{\prime}}{\tau_{b, c r .2}}\right)^{1.5} I_{2}\right] . \\
& I_{1}=\int_{0}^{\infty} x^{1.5} e^{-(x-r)^{2} / 2} d x, I_{2}=-\int_{0}^{\infty} x^{1.5} e^{-(x-p)^{3} / 2} d x
\end{aligned}
$$




\section{NUMERICAL PROCELURE AND RESULTS}

The mathematical model was applied to simulate numerically the morphological processes for an experiment flume. The numerical solution was obtained by using Runge Kutta Method for equations determining $u_{h}, \varepsilon_{f, \text { max }}$, then difference method with Crank Nilcolson and Spline's interpolation for diffusion equation [1], and Lax scheme for bed deformation.

At the inflow boundary the equilibrium sediment concentration profiles and the logarithmic distribution velocity were used as the boundary conditions $\{1,4,6\}$ :

$$
\frac{c_{e}}{c_{a e}}= \begin{cases}\left(\frac{a}{\bar{z}} \cdot \frac{h \cdot z}{h-a}\right)^{Z} & \text { for } \frac{\bar{z}}{h}<0.5 \\ \left(\frac{a}{h-a}\right)^{Z} \cdot \exp \left(-4 Z\left(\frac{\bar{z}}{h}-0.5\right)\right), & \text { for } \frac{\bar{z}}{\bar{h}} \geq 0.5\end{cases}
$$

in which $Z=w_{s} /\left(\beta k u_{*}\right)=$ suspension parameter, the equilibrium concentration at the reference level, $c_{\iota t}$, is determined according to experiment formula proposed by Van Rijn

$$
c_{\imath 2 e}=0.015 \frac{d_{50}}{a} \frac{T^{1.5}}{D_{*}^{0.3}}, T=\frac{\left(u_{*}^{\prime}\right)^{2}-\left(u_{*, c r}\right)^{2}}{\left(u_{*, c r}\right)^{2}}, u_{*}^{\prime}=\frac{g^{0.5}}{C^{\prime}} \tilde{u}
$$

where $u_{*, c r}$ is the critical bed shear velocity according to Shields, and corresponding velocity profile

$$
u_{\varepsilon}=\frac{g^{0.5}}{\kappa C} \operatorname{Ln}\left(\bar{z} / z_{0}\right) \overline{\bar{u}}
$$

\section{Input data}

$\begin{array}{ll}\text { water depth at inlet } x=0 & h_{0}=0.39 \mathrm{~m} \\ \text { mean current velocity at inlet } x=0 & \bar{u}_{0}=0.51 \mathrm{~m} / \mathrm{s} \\ \text { ratio of sediment and fluid mixing coefficient } & \beta=1 \\ \text { particle diameters of bed material } & d_{511}=160 \mu \mathrm{m} \\ & d_{00}=200 \mu \mathrm{m} \\ \text { particle fall velocity of suspended sediment } & w_{*}=0.013 \mathrm{~m} / \mathrm{s} \\ \text { effective bed roughness } & k_{*}=0.025 \mathrm{~m} \\ \text { sedinent density } & \rho_{*}=2650 \mathrm{~kg} / \mathrm{m}^{3} \\ \text { fuid density } & \rho=1000 \mathrm{~kg} / \mathrm{m}^{3} \\ \text { angle of repose of bed material } & \phi=35^{\prime 2} \\ \text { porosity of bed material } & p=0.4 \\ \text { constant of Von Karnan } & \kappa=0.4 \\ \text { reference level } & a=0.0125 \mathrm{~m}\end{array}$

Some results of computation were illustrated in the figures 1 - 7. Fig. 1 and Fig. 2 present the field of velocity after 5 and 10 hours, Fig. 3 - Fig. 6 present the concentration distributions at $x=6 m$ corresponding to different time. It is seen that suspended sediment concentration is approximately equal to zero "pwards the surface. Finally, the prediction of bed deformation due to deposition in turn after 5,9 and 15 hours in comparision with the initial form was presented in Fig. 7 .

\section{CONCLUSION}

The computional results showed that the mathematical model is posible to apply to the practice. However, because of the stability and the accuracy of solution, the time and space steps chosen is quite small. Therefore the computing process is rather slow. It takes 2.5 minutes per a computional step for AT286, 1 minute for AT386 DX and 15 seconds for AT486 DX to predict the deformation of bed after 3 minutes. 


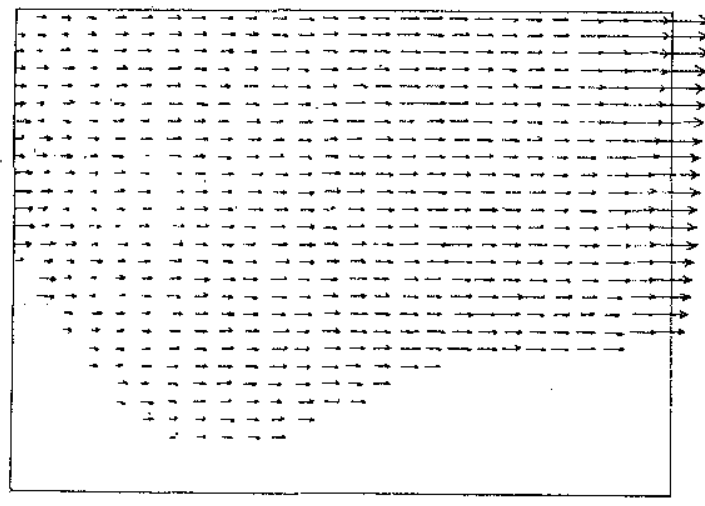

Fig. 1. Velocity field affiter 5 hours

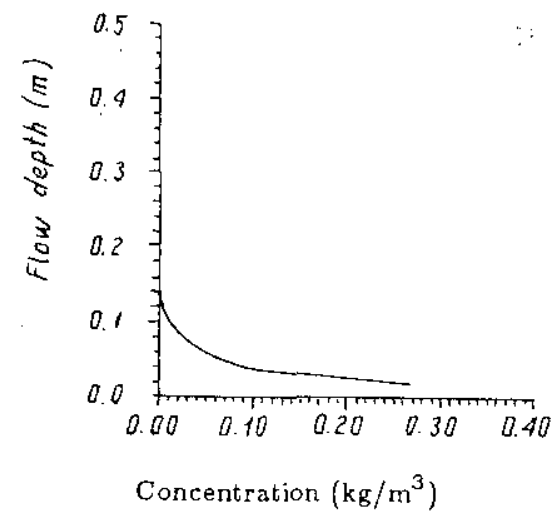

Fig. 3. Suspended concentration distribution at $x=6 \mathrm{~m}$ affter 1 hour

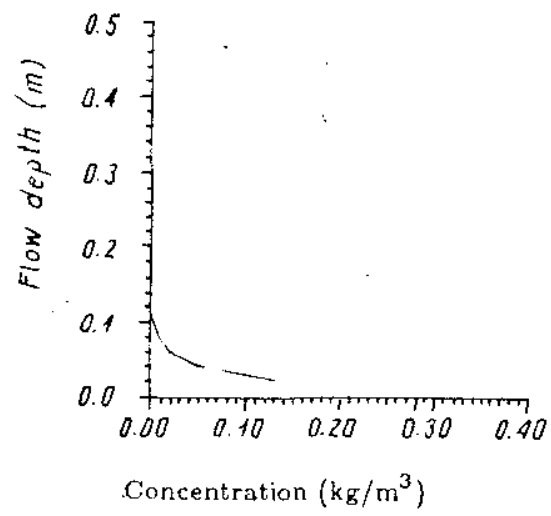

Fig. 5. Suspended concentration distribution at $x=6 \mathrm{~m}$ affter 10 hour

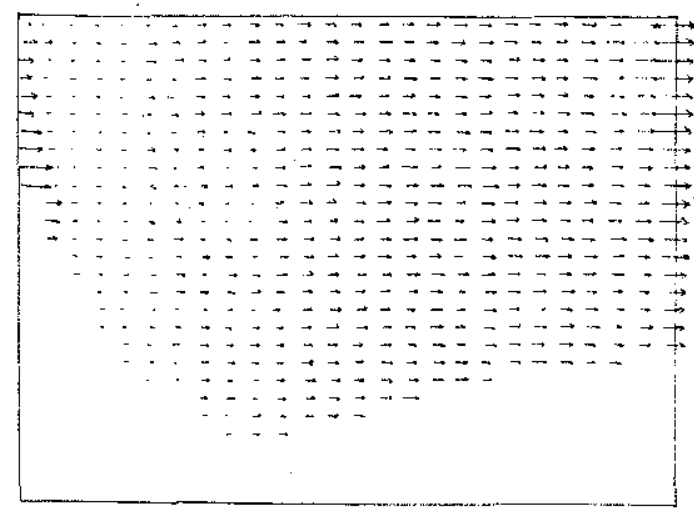

Fig. 2. Velocity field after 10 hours

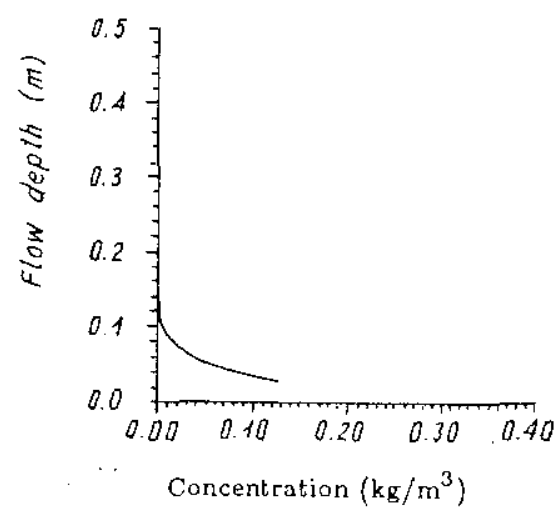

Fig. 4. Suspended concentration distribution at $I=6 \mathrm{~m}$ affter 5 hour

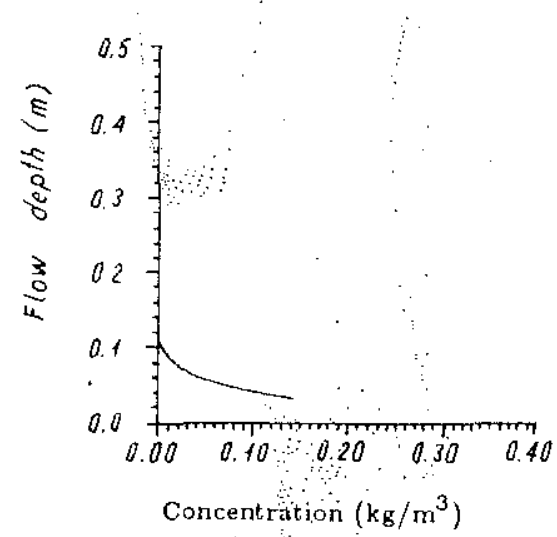

Fig. 6. Suspended concentration distribution at $x=6 \mathrm{~m}$ affter 15 hour 


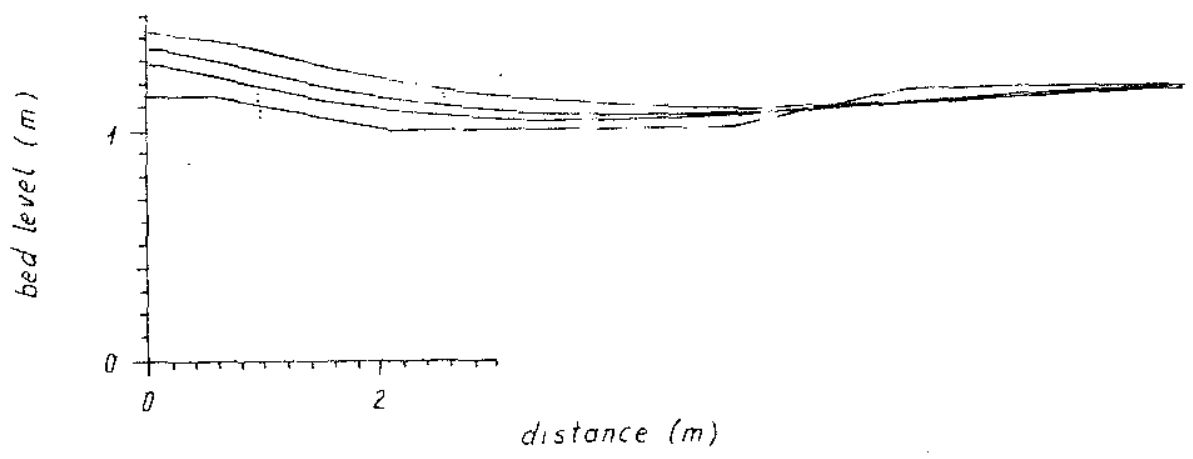

Fig. 7. Bed levels affter $0,5,9$ and $\mathbf{1 5}$ hours

This publication is completed with financial support from the National Basic Research Program in Natural Sciences.

\section{REFERENCES}

1. Dang Huu Chung. Suspended sediment concentration distribution in an alluvial channel flow. J. of Mechanics, No. 1, 1994.

2. Jorgen Fredsoe and Rolf Deigaard. The state of the art of predicting natural backfilling of sand in navigation channels. $11^{\text {th }}$ World Dredging Congress, Brighton 4-7 March 1986.

3. Kerssens P. J. M., Prins A. and van Rijn L. C. Model for suspended sediment transport. Journal of the Hydraulic Division, ASCE, HY5, May 1979.

4. Kerssens P. J. M. and van Rijn L. C. Model for non-steady suspended sediment transport. Publication No. 191, November 1977.

5. van Rijn L. C. Mathematical modelling of morphological processes in the case of suspended sediment transport. Ph. D. thesis, 1987, Netherlands.

6. van Rijn L. C. Mathematical modelling of suspended sediment in nonuniform flows. Delft Hydraulics Communication No.365, August 1986.

7. O'Connor B. A. Suspended sediment transport in the coastal zone. International Symposium on The Transport of Suspended Sediments And Its Mathematical Modelling. Florence (Italy), September 2-5, 1991.

Received Aprill 19, 1994

\section{MÔ PHÒNG SỐ QUÁ TRÌNH BIẾN ḊA ANG ĐỐI VỚI MỘT KÊNH GIAO THÔNG}

Phương pháp sai phân hữu hạn đã dược sử dụng để mô phóng số quá trình địa hình dối với một kênh giao thông. Các phương trinh toán học mô tả quá trình này dựa trên các mô hinh SUTRENCH và PROFILE do L. C. van Rijn đề nghị. Nhữug khó klıăn clo xừ lý diều kiện biên dộng đã được khắc phục nhờ sư dụng phrơng pháp nội suy Spline với dộ clínlı xác cao. Các kết quả nhận được chứng tó răng sự mô phóng rất phù hợp và có thể áp dụng để giải quyết các bài toán trong thực té. 